\title{
Probable Binary Fission in A Reed-Sternberg Cell
}

\author{
Shinichi Okuyama \\ Department of Radiology, Tohoku Rosai Hospital, Sendai \\ 981
}

Onuyama, S. Probable Binary Fission in a Reed-Sternberg Cell. Tohoku J. Exp. Med., 1991, 164 (3), 247-249 — A Reed-Sternberg cell in binary fission was observed in a case of Hodgkin's disease of nodular sclerosis type. This was thought to possibly represent a primitive eukaryotic manifestation or a retrograde replay of the endosymbiotic evolution of the modern eukaryotes as a part of devolution of malignancy (Okuyama and Mishina 1990).__ binary fission ; devolution; Hodgkin's disease ; primitive eukaryotism ; Reed-Sternberg cell

Devolution is one of the principal properties of neoplasms (Setala 1984 ; Okuyama and Mishima 1984, 1990), and locus minoris resistentiae is apt to arise resultantly (Setala 1984 ; Okuyama et al. 1987). We looked into the matter in a case of Hodgkin's disease (HD) in search for histologic evidence of devolution only to find a Reed-Sternberg (R-S) cell undergoing a binary fission. The patient was a 47-year-old man who developed mid-back pains along with an increasing numbness in the lower extremity. As he was found to have an extramedullary tumor of the spinal cord, surgery was carried out. The histologic diagnosis on the surgical specimen was HD of nodular sclerosis. When reviewed, there were a number of R-S cells, and one of them was found undergoing cell division as it was buried in the pleomorphic granulation tissue (Fig. 1). It was a binary fission rather than a mitosis: The nuclei were stretched out to form dumbbells before they gave rise to nuclear separation. It seemed different from the endomitosis, however. It is defined by failed distribution of chromosomes to daughter cells as cited (Therman et al. 1983). The chromosomes are dispersed throughout the nuclear body presumably as the result of absence or functional impairment of the asters and spindles. The observed R-S cell was octanucleated, but none of the nuclei, however, showed chromosomal formation. The paired nuclei were each undergoing an amitosis in the form of binary fission.

In the primitive eukaryotic cells, the nuclear division takes place completely being encased in the nuclear envelope, contrary to what happens to other modern eukaryotes (Koshihara 1979). In the latter, mitosis takes place after the nuclear envelope has dissolved. This type of changes have not been described except for budding (Stobbe 1983). The mononuclear Hodgkin and R-S cells are still capable of DNA synthesis (Kadin and Ashbury 1973; Wachi 1987). A tetraploid R-S cell may still be able to undergo mitosis (Ioachim 1975). But they may presumably cease to do so when they divide by budding or binary fission. Nanba and Sasaki (1990) seem to have started realizing the implications of the inconsistent immunological marker definition of R-S and $\mathrm{H}$ cells. Neoplastic transformation is well-known for its aptitude to lose its major constitutional antigenicity of the normal counterpart. Their common stem cell hypothesis may be attractive. Nonetheless, they did not postulate that the antigenic inconsistency may result from devolution but

Received February 14, 1991 ; revision accepted for publication May 30, 1991. 


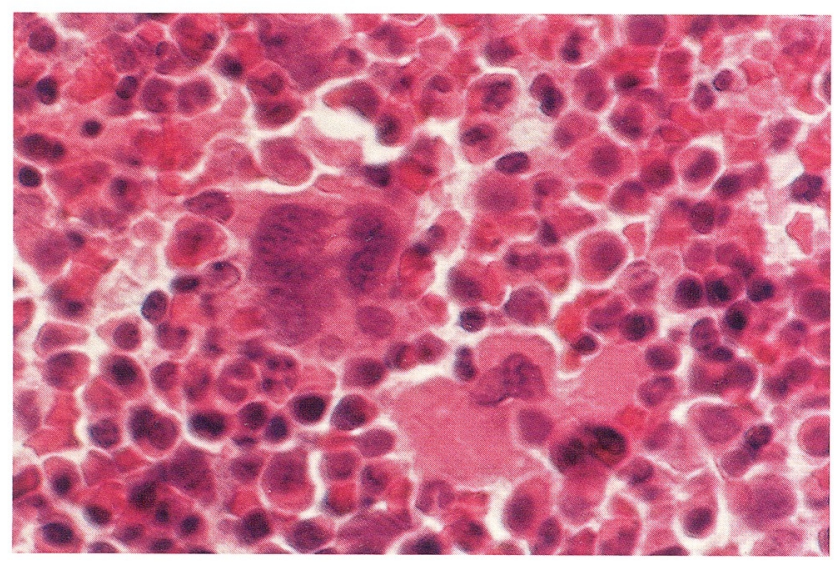

Fig. 1. Reed-Sternberg Cell in Binary Fission. This was a case of a man of 47-years-of-age who had developed an extramedullary tumor of the spinal cord. Histological diagnosis on the surgical material was Hodgkin's disease of nodular sclerosis type. When reviewed, one of the Reed-Sternberg cells was found undergoing a singular nuclear division different from mitosis as it was buried in the pleomorphic granulation tissue. The giant cell had four nuclei, three of which were stretched out to form dumbbells. The bottom most seems to have completed nuclear division. Although morphological ambiguity still remains, we may tentatively assume that in the absence of chromosomal arrangement, these 3 pairs of dumbbell nuclei were each undergoing an amitotic binary fission rather than endomitosis. This phenomenon, should it be verifiable, may possibly indicate a retrograde replay of endosymbiosis of the modern eukaryotes.

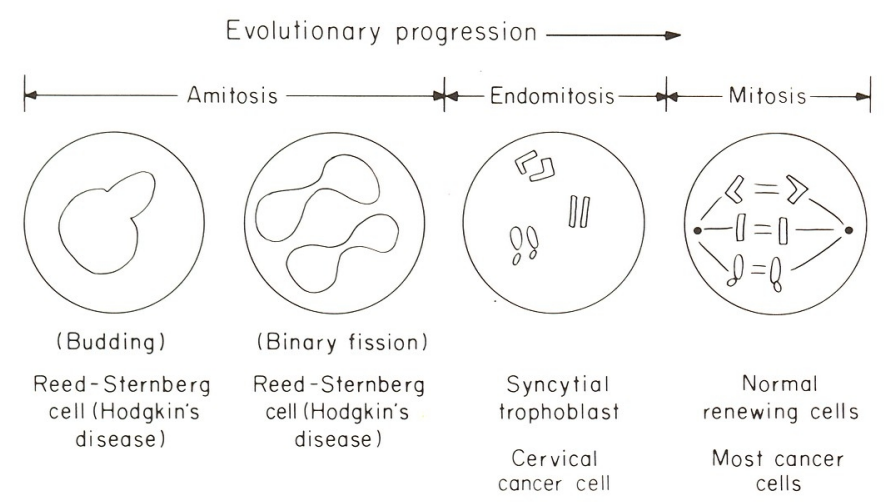

Fig. 2. Evolutionary Replay of Nuclear Division in Human Cells. The evolution of nuclear division could have progressed through those steps of amitosis and endomitosis before it reached the exact and efficient mitosis in which an exact duplication of the genetic information is secured and the resultant information is evenly distributed to daughters. Certain cellular morbidities may also help uncovering such evolutionary history of nuclear division. The probable structural defects may lie in the micro-tubular formation and function (Norberg 1970). 
rather from "immaturity" of the common stem cell. In addition, they did not discuss the possibility that R-S cell may emerge whenever any of the hematopoietic cell lineages, lymphocytic, histiocytic, granulocytic or else, devolve beyond certain critical stages of evolution as they excluded granulocytic candidacy based on the immunocytologic studies of their own. Observation of abnormalities in a single R-S cell itself may not necessarily tell the truth. Nonetheless, we may well expect a retrograde replay of the endosymbiotic evolution of the cell (Margulis 1981): (I) amitosis (budding (Stobbe 1983) and binary fission (this paper), both in R-S cells of HD ; (Il) endomitosis (syncytial trophoblast and cervical cancer cells (Therman et al. 1983)), and (III) mitosis (normal cells in the renewal systems, and most cancer cells) (Fig. 2). The nuclear division is closely related to the microtubular structure and function in both nuclear division and nuclear morphology (Norberg 1970). Then, the bizarre nuclear configurations to be seen in mycosis fungoides can also be considered along this line. The observation seems remarkable because it is a morphological confirmation of cancer devolution rather than biochemical (i.e., an increased water and a decreased superoxide dismutase content of cancer cells) or functional (viz., deficient DNA repair) (Okuyama and Mishina 1984, 1990). Further studies should strongly be encouraged.

\section{References}

1) Ioachim, H.L. (1975) New vistas in Hodgkin's disease. Pathol. Ann., 10, 419459.

2) Kadin, M.E. \& Ashbury, A.K. (1979) Long term cultures of Hodgkin's tissue. A morphologic and radioautographic study. Lab. Invest., 28, 181-184.

3) Koshihara, H. (1979) Gendai Saibo Seibutugaku. Shinka to Hikaku Seibutugaku wo Chuushin toshite, Baifukan, Tokyo. (in Japanese)

4) Margulis, L. (1981) Symbiosis in Cell Evolution. Life and Its Environment on the Early Earth, Freeman, San Francisco.

5) Nanba; K. \& Sasaki, N. (1990) Comparative pathology of giant cells in lymphoid malignancies: Evidences that they are proliferating stem cells. In : Lymphoid Malignancy: Immunocytology and Cytogenetics, edited by M. Hanaoka, M.E. Kadin, A. Mikata \& S. Watanabe, Field \& Wood Medical, New York, pp. 177-187.

6) Norberg, B. (1970) Cytoplasmic microtubules and radial-segmented nuclei (Rieder cells). Ultrastructural studies. Scand. J. Haematol., 7, 445-454.

7) Okuyama, S. \& Mishina, H. (1984) Evolutionary concepts of cancer and its evidence observable in the radiological sciences. Eizo Joho Medical, 16, 865-871. (in Japanese)

8) Okuyama, S. \& Mishina, H. (1990) Evolution of Cancer, University of Tokyo Press, Tokyo.

9) Okuyama, S., Mishina, H., Yoshizumi, A., Usuba, Y. \& Takahashi, M. (1987) Intratumoral doxycycline for skin metastases of human malignancies. Tohoku J. Exp. Med., 151, 241-244.

10) Setala, K. (1984) Carcinogenesis - Devolution towards an ancient nucleated pre-eukaryotic level. Med. Hypotheses, 15, 209-230.

11) Stobbe, H. (1983) Zur Zytogenese und Zytomorphologie der Hodgkin- und Sternberg-Reed-Zellen. Arch. Geschwulstforsch., 53, 115-123.

12) Therman, E., Sarto, G. \& Stubblefield, P.A. (1983) Endomitosis: A Reappraisal. Hum. Genet., 63, 13-18.

13) Wachi, E. (1987) Immunohistological and immunoelectron microscopic studies of Hodgkin's disease with special reference to Reed-Sternberg cell. Nichimokaishi, 27, 143-157. (in Japanese) 